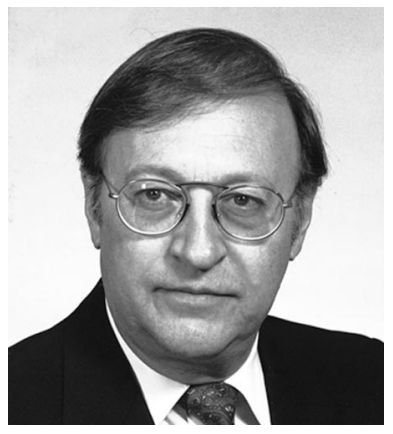

\section{Could Photonics Kill Optics, Part II?}

This month I would like to write a short editorial to respond to those who took some time to call me, to send e-mail, or to send me papers regarding my first editorial on this topic, which appeared in the March issue. First of all I thank them because it is very encouraging when I receive a call or a note, even if they do not all agree with me. However, this was not the case for this particular editorial. All the calls, e-mails, and letters had the same unified view of what is good for optical science and engineering.

Someone mentioned that an article on this topic was already published in the Proceedings of SPIE on Education in Optics in 1988, and it was written by a longtime editor of Optical Engineering. I must say that I very much enjoyed reading this paper, which was not known to me. With this paper in hand, I would not have written the editorial since all was said there. As I wrote in another previous editorial on the art of referencing, I did not do a complete job of reviewing all the papers already published on the subject. However, an editorial may be seen as a shaking box that enables a fire to start and by its very heat helps to generate new ideas.

Maybe this idea of optical science and engineering is not well viewed because some think that we must have just as much identification by subdomains. So, we must start a Society for Substrate Optics, a Society for Chalcogenide Films, etc. With the existence of those societies maybe we will be able to start a Federation of Societies. For those who think like that, I will ensure them that living in a federation is not a very easy task.

Fortunately, we have with SPIE a "Society for People Interested in Everything," as it has already been called. Isn't it marvelous? This society that rapidly responds to new ideas and new fields is permitting the use of optics as an enabling science in many fields. Hopefully for us, the report "Harnessing Light" comes to the same conclusion.

Let's dream of the new field of optical science and engineering to which we will be able to apply for grants.

Roger A. Lessard Editor 